Accepted manuscript of: David M. Smith, Charlotte Friend, Joanne Reeve. Polypharmacy and rationalisation of medications. InnovAiT: Education and inspiration for general practice. (C) The Author(s) 2020. DOI: 10.1177/1755738019890003

\title{
Polypharmacy and rationalisation of medications
}

Dr David M. Smith

ACF GPST2, Hull University Teaching Trust, Hull Royal Infirmary, Anlaby Road, Hull, HU3 2JZ Email: DavidMark.Smith@nhs.net

Twitter: @Dr_DM_Smith

Dr Charlotte Friend

ACF GPST1, Hull University Teaching Trust, Hull Royal Infirmary, Anlaby Road, Hull, HU3 2JZ Email: hycf1@hyms.ac.uk

Twitter: @Doctor_Friend_

Professor Joanne Reeve

Academy of Primary Care, Hull York Medical School

Email: joanne.reeve@hyms.ac.uk

Twitter: @joannelreeve

Corresponding author:

Joanne Reeve

Address: Academy of Primary Care, Hull York Medical School, University of hull, Cottingham Road, Hull HU6 7RX

Email: joanne.reeve@hyms.ac.uk

Phone: 01482463297 


\section{Polypharmacy and rationalisation of medications}

Growing numbers of people live with multi-morbidity. As patients' lists of co-morbidities grow, so do the list of an individuals' medications. Polypharmacy presents a significant challenge for individuals and their clinician. Polypharmacy can be appropriate, improving quality of life and life expectancy. But problematic polypharmacy is a growing burden, especially for patients living with frailty. The task of trying to rationalise what may be an extensive list of medications in a ten minute appointment seems like an impossible task. Guidance and support specifically aimed at trainees is limited. This article offers a starting point for GP trainees to stimulate their own exploration of this rapidly evolving field.

INSERT CURRICULUM BOX HERE

Polypharmacy: the challenge for trainees

Polypharmacy - the use of multiple medication in a single individual - is now a routine clinical intervention in many patients. Appropriate Polypharmacy (see Box 1) can improve health and wellbeing. But Inappropriate Polypharmacy (Box 1) can create challenges for patient and GP alike. To illustrate what we mean by problematic polypharmacy we will consider the case of Bob - a frail patient with complex multimorbidity and an extensive medication list (Box 2).

\section{INSERT BOX 1 HERE}

INSERT BOX 2 HERE

This consultation with Bob raises many questions. It appears Bob is burdened with the use of regular laxatives, due to his on-going opioid use, and possibly by the use of multiple antihypertensives. There is a question about whether his use of steroids has contributed to his dyspepsia symptoms. Can the steroids be titrated down in light of the PMR diagnosis? What effect has the ibuprofen had on both his dyspepsia and his kidney function? How can we educate the patient about the complex effects of these medications on the body? The patient wants antibiotics to treat his abdominal pain, now. How can we navigate all these issues for the patient? Above all else, how do we all this in whatever is left of the ten minute appointment slot?

Within this array of questions, a number of core GP principles are highlighted: the importance of exploring and checking patient understanding and expectations, and the importance of follow up and review of both medication and diagnoses in patients with long-term conditions. Many of the challenges in polypharmacy consultations can thus be managed using good General Practice consultation skills. Managing polypharmacy requires evidence-based knowledge of not only the mechanisms of action of medication, their side-effects and interactions, but also an understanding of how multiple medical issues affect our patients. 
Polypharmacy, however well intentioned, is far from benign and is associated with increased risks of adverse drug reactions (ADRs). A team using data from the UK Biobank project (Hanlon et al, 2018), identified that patients with COPD who were also suffering from other comorbidities were more likely than similar patients without COPD to be prescribed medication contributing towards falls, constipation, urinary retention, CNS depression, bleeding and renal injury. We prescribe opioids for pain relief which causes constipation and in turn we then prescribe laxatives for the treatment of constipation. However, elderly patients on laxatives are twice as likely to fall (Bloch et al, 2010). Thus we have increased the patients' risk of injury and hospital admission. It is not only the use of medicines associated with ADRs which is of concern to the clinician. Evidence indicates 5-20\% of prescriptions contain errors (Avery et al, 2012). The more medications a patient is taking, the higher the chance that one of these prescriptions will contain an error. latrogenic illness in patients with multi-morbidity can cause considerable harm. We must be mindful of how we educate patients to the risks and benefits of on-going medications, so that they are able to make informed decisions about the management of their own health conditions.

Applying the principles of evidence-based practice for appropriate polypharmacy (Box 1), using the patient-centred consultation skills of the excellent GP, therefore offers us a good starting point for managing this consultation with Bob. We must not find ourselves becoming complacent with repeat medication prescribing and ensure that regular follow-ups are booked for patients to evaluate if long term prescribed medications are still in the patient's best interests. The value of continuity of care comes to the fore in management of polypharmacy in General Practice. Box 3 offers some suggestions for how you might approach the medication review process.

\section{INSERT BOX 3 HERE}

Bob was fortunate to see an excellent GP trainee who reviewed his PMR diagnosis, was able to wean him off his steroid and so discontinue many of the associated medication. But Bob still had raised blood pressure and was prescribed multiple antihypertensives. He came back to see the trainee (who he now regarded as his regular GP) and reported still feeling burdened by all his tablets. "Do I really need all these tablets doctor?", he asked.

Bob's question now comes into the complex territory of problematic polypharmacy (Box 2). The intended benefit from a medical perspective is to control BP, but Bob's perception of benefit may differ. We are in the territory of the potential need for compromise between the goals of medicine and the goals of the patient (Duerden et al, 2013)

\section{Polypharmacy: the challenge for patients}

Appropriate polypharmacy applies evidence-based medical practice to improve outcomes for patients. But a growing evidence base also highlights that what can be appropriate from a medical perspective, may be problematic from a patient/personal perspective (Denford et al, 2014)

Despite moving away from the age of paternal medicine and towards shared decision making, 
insufficient attention has been given to the demands placed on patients when complying with taking multiple medications. There is growing recognition of the burden for patients of taking multiple medicines, even when medically appropriately prescribed. The average number of items dispensed per head of population has risen from 15.5 (2007) to 20.0 (2016) (NHS Digital, 2019). This increase in prescribing is particularly high in the elderly with $10 \%$ of over 65 's being prescribed over 10 simultaneous medications (Guthrie and Makubate, 2012). Patients report feeling burdened by the work of taking their medicines: $40 \%$ of people taking five or more medicines a day report feeling burdened by their medication (Krska et al, 2018), which may account for why $30-50 \%$ of medications are not taken as intended. When we start to think about rationalization and optimization of medication use to support individual patient health and wellbeing we may need to recognise that the compliance of the patient may be more of a key to delivering optimised care than adding a second antihypertensive, for example.

The patient's perspective on their medication is an important consideration for clinicians. A patient with too many medications may frequently miss doses. Patients who become fed up with taking too many pills many choose to omit ones which they feel offer no benefit. This may be particularly true for medications used in primary prevention where, if the medications work effectively, the patient will never experience any benefit from their baseline. Compliance can also be impaired by a significant side-effect profile, which is more likely to be the case with polypharmacy. Just because it is biomedically appropriate to prescribe, doesn't mean it is right for the patient. We may sometimes forget that there is more to our patient's lives than taking pills! Patient experience is essential to developing appropriate prescribing guidelines, yet it is often overlooked. A review of reports on medicines optimisation published by the Royal Pharmaceutical Society (RPS), The King's Fund and National Institute for Health and Social Care Excellence between 2013 \& 2017 (Heaton et al, 2017) showed a poverty of attention to the issue of the patient experience in published guidelines on medication use. In fact only The King's Fund considered evidence from qualitative studies of people's use of medicines. This highlights an important issue with evidence-based guidelines. Broad guidelines are written, which aim to provide the best care for the majority of the cohort in question but this occurs at the expense of truly individualised care. The good clinician knows when to deviate from these guidelines to provide optimized care for their patient.

Finding solutions: rethinking how we use medicines for person-centred care

So how do we find a way to better optimise medication use for our patients? Individualisation of prescribing is key to safe and effective prescribing in multi-morbidity. However, there is a lack of clarity in the literature over what direction individualisation should take (Denford et al, 2014). There is much research focused on the exciting field of pharmacogenetics but little attention on studies involving how patients and clinicians can work together to create optimised person-centred treatment plans. Denford et al suggest "mutually agreed tailoring" as a method of developing treatment plans with patients. These plans encourage patients to take a greater role in their own care including: having more knowledge about side-effect profiles (including advice on which side-effects may be tolerable), how to monitor medication effects at home and having an input into what times are best to take their medications. 
Trainees - and indeed the wider profession - need more help/guidance in IDENTIFYING who is burdened rather than benefited by their medicines, and so MANAGING deprescribing in situations when they want to discuss with patients about stopping tablets. Yet the evidence base on what to do and how is limited (Avery, 2019), which perhaps explains why clinicians describe finding it hard to tailor medication to individual patient needs in practice. A recent study examined professional barriers to tailoring medication (Reeve et al., 2018). GPs reported generally see their objectives as starting medications, in line with guidelines \& patient expectations. As stopping medications requires more cognitive input than following well used guidelines for commencing medications, clinicians reported not having the headspace during busy practice times to engage with rationalisation of medications as much as they would like. GPs expressed concern about the lack of professional training given around the topic of deprescribing. Finally, physicians expressed anxiety about working outside of (and in some cases directly against) guidelines. Specifically in light of a growing litigation culture, GPs felt that it may leave them vulnerable to future consequences.

There are now a number of tools being developed to support the clinician in rationalising medications. The evidence base demonstrating population level impact on medication load and mortality outcomes remains limited (Avery \& Bell, 2019) with one meta-analysis suggesting a decrease in medication to the tune of only 0.2 drugs per patient on average following the use of such tools. Another meta-analysis of randomised trials showed no overall reduction in patient mortality from such interventions (Page et al, 2016). However, the tools do potentially help individual clinicians and patients work together to safely achieve person-centred medication decisions.

This is a rapidly evolving area. Our intention is just to give you a starting point, heads up. Some references/reading to help you tackle each of these challenges. Box 5 offers some tools for you to look at.

\section{INSERT BOX 4 HERE}

Gaps still to fill: a rapidly evolving field of practice

Education around deprescribing is starting to be rolled out as part of junior doctor training (Poots et al, 2017). Tools are available to the clinician to aid with overcoming the problems associated with polypharmacy. These tools are varied and with some interrogation of the literature the clinician is likely to find a tool which fits appropriately with their own practice. These tools are far from perfect however. Reviewing a patent's medication in a systematic way is a significantly time-consuming process and may be complicated by patients who suffer from cognitive impairment or poor understanding of how their medications work. Involving carers or nursing home staff may also be required to effectively rationalise medications and ensure they are optimised to the individual patient's needs.

It would be neglectful to review the field of rationalisation without commenting on the ongoing crisis 
in the GP workforce. As mentioned in the results of the survey undertaken by Reeve et al (2018), GPs want to engage more with deprescribing and individualisation of prescribing but feel limited by the lack of time in a busy day. With 32\% of GPs reporting burnout (Patel, 2019) there needs to be consideration of how GPs can incorporate new styles of working into practice. Neural networks and deep learning may offer assistance to the over-burdened GP. A team in Stanford, USA (Zitnik et al, 2018) has developed a neural network named Decagon which looks at not only documented sideeffect profiles of medications but also at protein-protein interactions to predict side-effects associated with polypharmacy. Such tools, which can be used to alert the GP to interactions which they may otherwise miss in high-pressure short-duration consultations, will be invaluable as polypharmacy continues to increase in prevalence.

GPs no longer work alone in practices. The rise of the multi-disciplinary team has successfully eased the pressure on GP workloads across the country. It need not be the case that all the work associated with rationalising medications and identifying those most at risk from the perils of polypharmacy falls entirely on the shoulders of the GP. Those practices with resident pharmacists will be able to utilise these staff to work pragmatically to tackle this problem. As the new GP deal contains funding for 20,000 new staff (NHS England, 2019), this would be the time to strike when the proverbial iron is hot and embed rationalisation of medications and identification protocols for problematic polypharmacy into everyday practice. This is a sentiment echoed by our pharmacist colleagues (McClay \& Gymiah, 2019).

\section{CONCLUSION}

Managing polypharmacy - especially problematic polypharmacy - is a challenge for trainees and qualified clinicians alike. Many of the issues arising can be dealt with using good evidence-based medicines management, and the core principles of good general practice including whole person assessment, good communication skills and continuity of care.

But problematic polypharmacy also challenges medical practice to pay greater attention not only to the disease that people have, but to the delivery of whole person care - the principles and practice of expert generalist medicine. Tools and ways of working are emerging. But the needs of patients is evolving faster than the evidence for practice. For trainees and GPs alike, it is important to work with your full team to describe, deliver and learn from this emerging area of practice .

Key points

- Remember the principles of good General Practice to deliver person-centred care: explore your patients' ideas, concerns and expectations about their medicines; explicitly ask them if they feel burdened; invite them to work with you to identify possible areas for compromise

- Find tool(s) that work for you in your practice: there are a growing number out there and they are not all the same. Have a look and choose the one that works best for you. Try it out in practice and reflect with your trainer on what you are learning 
- Remember you are part of a team: These are complex decisions. They need critical, collaborative, and thoughtful responses. Talk with your team - other GPs, pharmacists. We're all in it together!

\section{References}

Avery, A., Barber, N., Ghaleb, M., et al. (2012b). Investigating the Prevalence and Causes of Prescribing Errors in General Practice: The PRACtICe Study. General Medical Council [online]. Available at: www.gmc-uk.org/about/research/12996. asp [Accessed 30 August 2019].

Avery, A.J., Bell, B.G. (2019). Rationalising medications through deprescribing. BMJ, 364:1570. DOI: 10.1136/bmj.1570.

Barber, N.D., Alldred, D.P., Raynor, D.K., et al. (2009). Care homes' use of medicines study: prevalence, causes and potential harm of medication errors in care homes for older people. BMJ Quality \& Safety, Volume 18 (5), pp 341-6. DOI: 10.1136/qshc.2009.034231.

Boyd, K., Murray, S.A. (2010). Recognising and managing key transitions in end of life care. British Medical Journal, Volume 341, c4863. DOI: 10.1136/bmj.c4863.

Bloch, F., Thibaud, M., Dugué, B., et al. (2010). Laxatives as a Risk Factor for latrogenic Falls in Elderly Subjects. Myth or Reality? Drugs \& Aging, Volume 27 (11): pp 895-901. DOI: 10.2165/11584280000000000-00000.

Denford, S., Frost, J., Dieppe, P., et al. (2014). Individualisation of drug treatments for patients with long-term conditions: a review of concepts. BMJ Open, Volume 4 (3):e004172. DOI: 10.1136/bmjopen-2013-004172.

Duerden, M., Avery, T., Payne, R. (2013). Polypharmacy and medicines optimisation Making it safe and sound. Kings Fund. Available online:

https://www.kingsfund.org.uk/sites/default/files/field/field publication file/polypharmacy-andmedicines-optimisation-kingsfund-nov13.pdf [Accessed 29th Aug 2019]

Gold Standard Framework (2013). Resources [online] available from: www.goldstandardsframework.org.uk/ [Accessed 29th Aug 2019]

Guthrie, B., Makubate, B. (2012). The rising tide of polypharmacy and potentially serious drug interactions 1995-2010: repeated cross sectional analysis of dispensed prescribing in one region. Primary Health Care Research \& Development, Volume 13, sup S1:45 SE.2. DOI: 10.1186/s12916015-0322-7.

Hanlon, P., Nicholl, BI., Jani, BD., et al. (2019). Examining patterns of multimorbidity, polypharmacy and risk of adverse drug reactions in chronic obstructive pulmonary disease: a cross-sectional UK 
Biobank study. BMJ Open, Volume 8 (1):e018404. DOI: 10.1136/bmjopen-2017-018404.

Heaton, J., Britten, N., Krska, J., Reeve, J. (2017). Person-centred medicines optimisation policy in England: an agenda for research on polypharmacy. Primary Health Care Research and Development, Volume 18(1): 24-34. DOI: 10.1017/S1463423616000207.

Katusiime, B., Corlett, S.A., Krska, J. (2018). Development and validation of a revised instrument to measure burden of long-term medicines use: the Living with Medicines Questionnaire version 3. Patient Related Outcome Measures Journal. Volume 9: pp155-168. DOI: 10.2147/PROM.S151143.

Krska, J., Katusiime, B., Corlett, S.A. (2018). Patient experiences of the burden of long-term medicines use and factors affecting burden: a cross-sectional survey. Health and Social Care in the Community, Volume 26 (6): pp946-959. DOI: 10.1111/hsc.12624.

McClay, E., Gyimah, C. (2019). Pharmacists must work with others to roll back polypharmacy culture. Clinical Pharmacist. Available online at: https://www. pharmaceuticaljournal.com/opinion/insight/pharmacists-must-work-with-others-to-roll-back-polypharmacyculture/20206704.article?firstPass=false [Accessed 30th Aug 2019]

NHS Digital. (2019). Prescriptions Dispensed in the Community - Statistics for England, 2007-2017. NHS Digital. Available online: https://digital.nhs.uk/data-andinformation/publications/statistical/prescriptions-dispensed-in-the-community/prescriptionsdispensed-in-the-community-england---2007---2017\#key-facts [Accessed 29th Aug 2019]

NHS England. (2019). Five-year deal to expand GP services and kick start NHS Long Term Plan implementation. NHS England News. Available online at: $h t t p s: / / w w w . e n g l a n d . n h s . u k / 2019 / 01 / f i v e-$ year-deal-to-expand-gp-services-and-kick-start-nhs-long-term-plan-implementation/ [Accessed 30th Aug 2019]

NHS Scotland. (2018). Polypharmacy Guidance Realistic Prescribing $3^{\text {rd }}$ Edition. Available online at: https://www.therapeutics.scot.nhs.uk/wp-content/uploads/2018/04/Polypharmacy-Guidance2018.pdf [Accessed 30th Aug 2019]

O'Mahony, D., O'Sullivan, D., Byrne, S., et al. (2015). STOPP/START criteria for potentially inappropriate prescribing in older people: version 2. Age Ageing, Volume 44(2): pp213-218. DOI: 10.1093/ageing/afu145.

Oxfordshire Clinical Commissioning Group. (2017). Prescribing Rationalisation Clinical Tool. Available online at: https://clinox.info/clinical-support/local-pathways-andguidelines/Clinical\%20Guidelines/Prescribing\%20Rationalisation\%20Clinical\%20Tool.pdf [Accessed $29^{\text {th }}$ Aug 2019]

Page, A.T., Clifford, R.M., Potter, K., et al. (2016). The feasibility and effect of deprescribing in older adults on mortality and health: a systematic review and meta-analysis. British Journal of Clinical Pharmacy, Volume 82: pp583-623. DOI:10.1111/bcp.12975 pmid:27077231. 
Patel, A. (2019). One in three GPs suffer from burnout due to workload, figures show. Pulse. Available online at: http://www.pulsetoday.co.uk/news/hot-topics/war-on-workload/one-in-three-gps-sufferfrom-burnout-due-to-workload-figures-show/20038268. article [Accessed 30th Aug 2019]

Poots, A.J., Jubraj, B., Barnett, N.L. (2017). Education around deprescribing: 'spread and embed' the story so far. European Journal of Hospital Pharmacy, Volume 24 (1): pp7-9. DOI:10.1136/ejhpharm2016-001153.

Reeve, J., Britten, N., Byng, R., et al. (2018). Identifying enablers and barriers to individually tailored prescribing: a survey of healthcare professionals in the UK. BMC Family Practice, Volume 19 (1):17. DOI: 10.1186/s12875-017-0705-2.

Szczepura, A., Wild, D., Nelson, S. (2011). Medication administration errors for older people in longterm residential care. BMC Geriatrics, Volume 11: p 82. DOI: 10.1186/1471-2318-11-82.

Tower Hamlets Clinical Commissioning Group. (2014). Managing Medicines in the Last Years of Life. Available online from:

https://www.stih.org.uk/system/files force/files/MANAGING\%20MEDICINES\%20IN\%20THE\%20LAST \%20YEARS\%200F\%20LIFE.pdf?download=1 [Accessed 29 ${ }^{\text {th }}$ Aug 2019].

Wennberg, D., Siegel, M., Darin, B., et al. (2006). Combined predictive model: Final report and technical documentation. London: Department of Health, New York University, The King's Fund, Health Dialogue. Available online from:

https://www.kingsfund.org.uk/sites/default/files/field/field document/PARR-combined-predictivemodel-final-report-dec06.pdf [Accessed 30th Aug 2019]

Zitnik, M., Agrawal, M., Leskovec, J. (2018). Modeling polypharmacy side effects with graph convolutional networks. Bioinformatics, Volume 34 (13)L pp 457-466. DOI: 10.1093/bioinformatics/bty294. 
The RCGP curriculum and polypharmacy

Professional topic guide: Improving quality, safety and prescribing

The process of prescribing requires

- Targeted assessment of the patient and other sources

- An appropriately detailed understanding of the patient's history

- Wherever possible, an agreement with the patient and their carers on the treatment proposed

- That the prescription is in the patient's best interests, correctly and clearly prescribed, and accurately documented within the patient record

- Reviewed by a suitable healthcare professional at an appropriate time

Life Stages Topic Guide: Older adults

As a GP, your role is to

- Diagnose, investigate and manage older adults taking into account theories of ageing, differences in epidemiology and risk factors of disease in the elderly population

- Communicate appropriately with patients, their families and carers

- Coordinate with other organisations and professionals

- Review medications and repeat prescriptions effectively, potentially working with pharmacists.

- Ensure care promotes patients' sense of identity, independence, personal dignity and that the patient is not discriminated against as a result of their age.

Key knowledge and skills: recognising

- Co-morbidity and physical factors disproportionately affect the health of older people and will influence the management of existing disease

- A problem-based approach is important, taking in the 'big picture', rather than a diseasebased approach to the care of older people

- Risks of poly-pharmacy (including the increased risks of significant cross-reactions and side effects). 
Appropriate polypharmacy is defined as prescribing for an individual for complex conditions or for multiple conditions in circumstances where medicines use has been optimised and where the medicines are prescribed according to best evidence.

Problematic polypharmacy is defined as the prescribing of multiple medications inappropriately, or where the intended benefit of the medication is not realised. 
Bob is an 82 year old gentleman. He comes in on a busy Friday morning clinic to ask for some antibiotics. He states that he wants these for his "dicky tummy", as his friend is on them. Further probing reveals dyspepsia symptoms. Bob has an extensive medication list which includes three antihypertensives, regular co-codamol, senna, lactulose when needed and a repeat low-level oral steroid prescription. He tells you that these are for his gout and for ongoing constipation. He is also taking over-the-counter ibuprofen. Reading the notes reveals that Bob saw a rheumatologist several years ago and was diagnosed with polymyalgia rheumatica (PMR), which was when the steroids were started. He has since been lost to follow-up. He has had no blood tests for past 12 months. Bob is unfamiliar with the PMR diagnosis and asks when he will be prescribed his antibiotics. 


\section{BOX 3: Optimising medicines - a medication review check list}

Medication reviews can be done face to face with a patient, or through a review of the patient record. When you have completed a medication review you should clearly document in the patients notes for each medicine:

1. Why is this person on this medication?

Make sure you know when and why each medicine was started. Consider whether this person still needs this medication now and/or whether it will need to be stopped in the future? Ensure the reason for the medicine and planned duration of use is appropriately recoded in the patient record. Ask the patient if they know why they are on the medicine.

2. Is each individual medicine correctly prescribed?

If it is clinically appropriate for the medicine to be used, check: the dose, formulation, timing and duration of the prescription (ongoing or time bounded). Are there any errors in the writing of the prescription? Are alerts in place for blood tests and monitoring?

3. Are all medicines prescribed showing on the patients repeat prescription list?

For example, hospital issued medication (eg when a patient starts methotrexate) may not show on the GP prescription list unless specifically entered

4. Red flags - do you have concerns about the collection of medicines prescribed for this individual?

Check for drug interactions (which will usually show up in alerts). Are there any high risk medicines in the list (eg medicines that need monitoring, addictive medicines eg opiods etc)? Are there any potentially medically inappropriate medications? Do you need to see the patient face to face to explore any of these issues?

5. Is the patient using the medication as prescribed? Is the patient over or under using their medication? Both would prompt a request for the patient to come in to discuss their medication

6. Are there things I am not sure about? Maybe unfamiliar medication or conditions; red flags associated with complex or high risk issues? Do I need to discuss this with an experienced GP, a pharmacist, the hospital team? And most of all the patient.

Remember - you don't have to do all of this in ten minutes! 


\begin{tabular}{|c|c|c|}
\hline \multicolumn{3}{|c|}{ IDENTIFYING PATIENTS } \\
\hline $\begin{array}{l}\text { From the } \\
\text { clinician's } \\
\text { perspective: } \\
\text { STOPP START } \\
\text { criteria }\end{array}$ & $\begin{array}{l}\text { https://www.ncbi.nlm.nih.gov/p } \\
\text { mc/articles/PMC4339726/ }\end{array}$ & $\begin{array}{l}\text { Contains } 114 \text { criteria ( } 80 \text { Stop and } 34 \text { Start) } \\
\text { which either encourage the clinician to cease } \\
\text { or begin medications in patients }>64 \text { years } \\
\text { old. } \\
\text { This would be useful as a tool to run } \\
\text { periodically within a practice to audit/identify } \\
\text { problematic polypharmacy. }\end{array}$ \\
\hline $\begin{array}{l}\text { From the } \\
\text { patient's } \\
\text { perspective: } \\
\text { Living with } \\
\text { Medicines } \\
\text { Questionnaire }\end{array}$ & $\begin{array}{l}\text { https://www.dovepress.com/de } \\
\text { velopment-and-validation-of-a- } \\
\text { revised-instrument-to-measure- } \\
\text { burden-o-peer-reviewed-article- } \\
\text { PROM }\end{array}$ & $\begin{array}{l}\text { This survey can be given to patients and asks } \\
\text { them to rate a variety of factors relating to } \\
\text { their experience of medication use. Questions } \\
\text { are related to how medicines interfere with } \\
\text { the patient's life, side-effect profile, } \\
\text { perceived effectiveness of medications and } \\
\text { quality of communication with the clinician. } \\
\text { A particularly useful tool when medicines } \\
\text { seem not be to having the anticipated effect } \\
\text { (IE: When compliance may be an issue to } \\
\text { consider). }\end{array}$ \\
\hline \multicolumn{3}{|c|}{ MANAGING PRESCRIBING } \\
\hline $\begin{array}{l}\text { NHS Scotland } \\
\text { Polypharmacy } \\
\text { Guidance } \\
\text { Realistic } \\
\text { Prescribing }\end{array}$ & $\begin{array}{l}\text { https://www.therapeutics.scot.n } \\
\text { hs.uk/wp- } \\
\text { content/uploads/2018/04/Polyp } \\
\underline{\text { harmacy-Guidance-2018.pdf }}\end{array}$ & $\begin{array}{l}\text { A very detailed resource which contains } \\
\text { information on individual drugs (and } \\
\text { problems associated with polypharmacy to be } \\
\text { mindful of) but also contains resources for } \\
\text { methodology of how the trainee should } \\
\text { approach the area of rationalisation of } \\
\text { medications. } \\
\text { The 7-step approach to medicines review } \\
\text { (p14) is particularly useful for the clinician as } \\
\text { a quick-reference crib sheet. }\end{array}$ \\
\hline
\end{tabular}




\begin{tabular}{|c|c|c|}
\hline $\begin{array}{l}\text { Oxfordshire } \\
\text { Clinical } \\
\text { Commissioning } \\
\text { Group, } \\
\text { Prescribing } \\
\text { Rationalisation } \\
\text { Clinical Tool }\end{array}$ & $\begin{array}{l}\text { https://clinox.info/clinical- } \\
\text { support/local-pathways-and- } \\
\text { guidelines/Clinical\%20Guidelines } \\
\text { /Prescribing\%20Rationalisation\% } \\
\text { 20Clinical\%20Tool.pdf }\end{array}$ & $\begin{array}{l}\text { A condensed tool, focusing on key areas of } \\
\text { problematic prescribing found in the } \\
\text { Oxfordshire area. Similar tools may exist } \\
\text { within other CCGs. } \\
\text { By focusing the guidance to align with local } \\
\text { issues the tool is simple to utilise (it is only } 10 \\
\text { pages long) and allows the clinician to direct } \\
\text { their time towards the key problems in their } \\
\text { locality. }\end{array}$ \\
\hline $\begin{array}{l}\text { Tower Hamlets } \\
\text { Clinical } \\
\text { Commissioning } \\
\text { Group: Managing } \\
\text { Medicines in the } \\
\text { Last Years of Life } \\
\text { Decision Support } \\
\text { Guidance for } \\
\text { Health } \\
\text { Professionals in } \\
\text { North East } \\
\text { London }\end{array}$ & $\begin{array}{l}\text { https://www.stjh.org.uk/system } \\
\text { /files force/files/MANAGING\%2 } \\
\text { OMEDICINES\%20IN\%20THE\%20L } \\
\text { AST\%20YEARS\%20OF\%20LIFE.pd } \\
\text { f?download=1 }\end{array}$ & $\begin{array}{l}\text { A tool focusing on rationalising medications } \\
\text { as patients approach the end of life. Broken } \\
\text { down into } 10 \text { broad pathological categories } \\
\text { (Diabetes, Respiratory disease, Heart failure, } \\
\text { Cancer, Last days of life, etc) it offers } \\
\text { guidance to the clinician on which } \\
\text { medications to stop, continue and even which } \\
\text { medications to consider introducing. } \\
\text { Very detailed and useful guide. By focusing on } \\
\text { pathological domains rather than individual } \\
\text { classes of drugs, commonly associated drugs } \\
\text { are considered together, making the guidance } \\
\text { instinctively more applicable to practice. }\end{array}$ \\
\hline $\begin{array}{l}\text { Gold Standards } \\
\text { Framework }\end{array}$ & $\begin{array}{l}\text { www.goldstandardsframework.org. } \\
\text { uk/ }\end{array}$ & $\begin{array}{l}\text { Whilst rationalization of medications at the } \\
\text { end of life may be done quite well in the very } \\
\text { acute setting (where the patient has days or } \\
\text { short weeks to live), it is often overlooked in } \\
\text { the patients who may not formally be on a } \\
\text { palliative pathway. Use of the question: } \\
\text { "Would I be surprised if this person were to } \\
\text { die in the next } 12 \text { months?" (Boyd \& Murray } \\
2010 \text { ), is useful for prompting the clinicians to } \\
\text { consider engaging the patient in a discussion } \\
\text { surrounding discontinuation of medications. } \\
\text { Tools are available on the Gold Standards } \\
\text { Framework website to aid clinicians in holding } \\
\text { these difficult discussions. }\end{array}$ \\
\hline
\end{tabular}


